\title{
Investigation an assisting electrode powder mixed electrical discharge machining of nonconductive ceramic
}

\section{Dragan Rodic ( $\square$ rodicdr@uns.ac.rs)}

University of Novi Sad: Univerzitet u Novom Sadu https://orcid.org/0000-0001-9777-9185

\section{Marin Gostimirovic}

University of Novi Sad: Univerzitet u Novom Sadu

\section{Milenko Sekulic}

University of Novi Sad: Univerzitet u Novom Sadu

\section{Borislav Savkovic}

University of Novi Sad: Univerzitet u Novom Sadu

\section{Branko Strbac}

University of Novi Sad: Univerzitet u Novom Sadu

\section{Research Article}

Keywords: response surface methodology, hybrid assisting electrode, zirconium oxide, surface roughness, material removal rate, tool wear ratio

Posted Date: April 28th, 2021

DOl: https://doi.org/10.21203/rs.3.rs-408151/v1

License: (9) (1) This work is licensed under a Creative Commons Attribution 4.0 International License. Read Full License

Version of Record: A version of this preprint was published at The International Journal of Advanced Manufacturing Technology on September 29th, 2021. See the published version at https://doi.org/10.1007/s00170-021-08061-8. 


\section{Abstract}

It is well known that electrical discharge machining can be used in the processing of nonconductive materials. In order to improve the efficiency of machining modern engineering materials, existing electrical discharge machines are constantly being researched and improved or developed. The current machining of non-conductive materials is limited due to the relatively low material removal rate and high surface roughness. A possible technological improvement of electrical discharge machining can be achieved by innovations of existing processes. In this paper, a new approach for machining zirconium oxide is presented. It combines electrical discharge machining with assisting electrode and powder-mixed dielectric. The assisting electrode is used to enable electrical discharge machining of nonconductive material, while the powder-mixed dielectric is used to increase the material removal rate, reduce surface roughness, and decrease relative tool wear. The response surface method was used to generate classical mathematical models, analyzing the output performances of surface roughness, material removal rate and relative tool wear. Verification of the obtained models was performed based on a set of new experimental data. By combining these latest techniques, positive effects on machining performances are obtained. It was found that the surface roughness was reduced by $18 \%$, the metal removal rate was increased by about $12 \%$ and the relative tool wear was reduced by up to $6 \%$ compared to electrical discharge machining with supported electrode without powder.

\section{Introduction}

Despite its exceptional properties compared to metallic materials, ceramics are gradually gaining acceptance in the manufacturing industry. One of the reasons for this is related to the sintering process, which limits the production of complex geometries, as well as limiting the machinability of the final product. Various processes can be used to machine ceramic materials, such as diamond tool grinding, ultrasonic machining, laser machining, water abrasive machining, ion beam machining, etc. [1, 2]. However, these machining methods have some limitations in terms of productivity, quality, and economy of machining, i.e., they do not fully meet the requirements of modern production. Therefore, it is necessary to consider other methods by which ceramic materials can be machined.

Electrical Discharge Machining (EDM) is a machining process that can process all electrically conductive materials, regardless of their physical and metallurgical properties [3]. To machine electrically nonconductive materials by EDM, electrical contact should be established [4]. This is solved by the method of assisting electrodes, which helps to start the discharge between tools and non-conductive materials. Discharges can continue if maintaining favorable conditions for the creation of a secondary electrically conductive layer [5].

From the existing literature by applying an electrically conductive layer (Assisting Electrode - AE) to the top of the workpiece, it is possible to machine electrically non-conductive ceramic materials with the designation Assisting Electrode Electrical Discharge Machining (AEEDM). The detailed description of EDM technology with the assisting electrode in the academic circles was recorded in 1995 by Japanese 
scientists Fukuzawa et al [6]. In their work, a new method was described that enabled electrical discharge machining of electrically non-conductive ceramic materials using an adhesive metal plate (assisting electrode) placed on the workpiece. They concluded that AEEDM is realized by modifying the ceramic surface, i.e., continuously forming an electrically conductive layer. The assisting electrode enables an initial electrical discharge between the tool and the workpiece. After the assisting electrode layer is removed by the high temperature in the discharge zone, dielectric dissolution occurs, whereupon the carbon particles are deposited on the surface and form an electrically conductive layer (carbon layer). During the AEEDM process, an electrically conductive carbon layer is continuously formed on the workpiece, which is responsible for the stability of the process [7]. The process of formation of the electrically conducting layer is also described by [8]. Here it is mentioned that the dielectric oil must be carbon based for the erosion of non-conductive ceramics to be stable. Similar phenomena have been noted by the Mohri et al [9].

The AEEDM process is illustrated in Fig. 1. The surface of the workpiece is covered with an electrically conductive material, allowing the first electrical discharge, i.e. the discharge between the tool and the assisting electrodes. Thereafter, the discharge is continuous through the conductive layer to the workpiece material on which the carbon layer (pyrolytic layer) is produced. During the electrical discharge process, a conductive carbon layer is continuously generated on the workpiece, which is responsible for the stability of the process.

The influence of the material AE on the technological properties of AEEDM was analyzed by Tani et al [10]. In this work, a comparison of different designs of supported electrode is carried out, first with a metal plate and then with a metal grid applied in several layers. It was found that the application of a copper grid significantly reduces the surface roughness. The same authors [7] processed zirconium oxide $\mathrm{ZrO}_{2}$ with copper and graphite tools. They found that the carbon layer was not fully formed when copper tools were used, resulting in a rough surface roughness. In the next work [11] the effect of thermal conductivity of alumina with purity of $99.99 \%$ on machining productivity was studied. At higher values of thermal conductivity of the material, higher machining productivity is achieved. In [12] the die-sinking EDM of alumina with high discharge energy was carried out. High discharge voltage and very high capacitance per unit area was used, which resulted in very high discharge energy and explosive force. They concluded that tool polarity is the most important factor affecting crater volume and depth, as well as relative tool wear. Sabur et al defined that the formation and stability of the carbon layer (in addition to the material of the workpiece and tools, the type of dielectric and the polarity of the tool) is influenced by the discharge energy, which is the product of voltage, discharge current and pulse duration [13].

Significant input parameters affecting machining performances were studied by Chen et al [14]. They showed that discharge current and pulse duration significantly affect and $R_{a}$. In addition, they used two types of assisting electrodes, aluminum and copper, and concluded that the type of electrodes had a high effect on TWR. 
However, the current application of AEEDM is limited due to the relatively low material removal rate and high surface roughness. AEEDM of electrically nonconductive materials by adding an electrically conductive powder to the dielectric results in a hybrid process called Assisting Electrode Powder Mixed Electrical Discharge Machining ((AE + PM) EDM). It is believed that the addition of electrically conductive powder reduces the insulating properties of the dielectric, resulting in an increase in the working gap, thus achieving more efficient flushing of the working space between the tool and the workpiece.

The first basic technology of electrical discharge machining with an assisting electrode in powder mixed dielectric was set in 2002 by scientists Tani et al [15]. Using the method ((AE + PM) EDM) with several types of powders of different sizes (silicon powder, nickel powder, graphite powder, aluminum powder and zirconium boride powder), they successfully machined insulating silicon nitride ceramic $\left(\mathrm{Si}_{3} \mathrm{~N}_{4}\right)$. The results obtained show that the machining productivity was improved by using all five types of powders. However, contrary to their expectations, there was no significant improvement in the surface roughness, as a longer pulse duration was generated during machining than was primarily set on the machine. This phenomenon is common in EDM of high strength materials. They concluded that reducing the pulse duration below the value of $24 \mu$ s improves the surface roughness. In this way, the excessive pulse duration is prevented, which directly affects the increase in discharge energy. The investigation of the surface roughness in the (AE + PM) EDM was also caused by Sabur et al [16]. The discharge voltage and powder concentration of tantalum carbide $(\mathrm{TaC})$ were input variable, while other parameters were maintained at a constant level. Modeling and analysis were performed using the response surface methodology. It was observed that the discharge voltage has a greater influence on the surface roughness than the powder concentration. The optimal values of discharge voltage and powder concentration, $94 \mathrm{~V}$ and $6 \mathrm{~g} / \mathrm{l}$, are also presented, where the minimum surface roughness is obtained. Also, the application of the process of (AE + PM) EDM is presented in paper [17]. In their work, several types of electrically non-conductive materials with an outer copper diameter of $3.5 \mathrm{~mm}$ and an inner diameter of $3 \mathrm{~mm}$ were processed in a dielectric with mixed graphite powder with a grain size of $30 \mu \mathrm{m}$. In the mentioned study, it is not clearly stated what is the contribution of the addition of graphite powder to the dielectric. Various materials were machined, some of which were electrical non-conductive, with only one machining regime $\left(I_{e}=1.5 \mathrm{~A}, t_{i}=50 \mu \mathrm{s}\right.$ and $\left.U_{0}=100 \mathrm{~V}\right)$. Raju et al performed wire EDM of insulating zirconia and also tested the feasibility of $A E+P M$ method [18]. They used the graphite additives to support the secondary electrically conductive layer formation and to have the uninterrupted sparking when the insulating ceramic surface is exposed. In their case, the most stable processing was achieved at a graphite powder concentration of $4 \mathrm{~g} / \mathrm{l}$.

The results of previous studies, of which there are not many, indicate that electrically nonconductive EDM materials have significantly lower machining productivity, higher surface roughness, and higher tool wear than metallic EDM materials. Due to the very difficult nature of conducting experiments, there are also very few mathematical models of the output performance for this type of machining. Therefore, the main contribution of this research is EDM of non-conductive material with an assisting electrode in a dielectric with mixed powder. One of the representatives of electrically non-conductive ceramics used in this 
research is zirconia - $\mathrm{ZrO}_{2}$. A combination of self-adhesive copper metal foil and graphite layer was used as the hybrid assisting electrode, while the dielectric is mixed with graphite powder. In this work, the aim is to demonstrate that by combining the AEEDM process with a mixed powder dielectric, an additional improvement in output performance is achieved when processing non-conductive ceramics. The main objective is to achieve practical application, develop mathematical models and find influence parameters for (AE + PM) EDM zirconium, such as $l_{e} t_{i}$ and $G R$, as a function of process performance $\left(R_{a}, M R R\right.$ and $T W R)$. For this purpose, the response surface methodology was applied.

\section{Materials And Methods}

The experiments in this research were designed to improve existing EDM. This is done by using methods such as supported electrode and powder mixed dielectric. All with the aim of improving machining performance such as surface roughness, material removal rate and relative tool wear when machining zirconium oxide. The flowchart, espoused in the present study to generate RSM models of output characteristics, is shown in Fig. 2.

In order to obtain adequate models of output characteristics, the study was conducted in several steps. Based on the available literature and the capabilities of the machine tool, the analysis and assumption of the input parameters was performed. Due to the unavailability of data on electrical discharge machining of non-conductive ceramics, preliminary tests were carried out to define the range of input parameters. Maximum values of the variable input parameters such as discharge current, pulse duration and graphite powder concentration were determined. In the next step, the main experiments were carried out according to the Box-Behnken Design. Using the analysis of ANOVA, the RSM models $R_{a}, M R R$ and TWR were constructed. After the verification of the model, the analysis of the influence of the input parameters on the output power was carried out, paying special attention to the influence of the addition of graphite powder to the dielectric.

\subsection{Machine, tool and workpiece}

A series of experiments was carried out on a die-sinking EDM machine Agie Charmilles of the SP1-U type. The isotropic graphite with a cross-section of $10 \times 10 \mathrm{~mm}^{2}$ was used as an electrode for machining insulating zirconium oxide $\mathrm{ZrO}_{2}$. The reason for using graphite tools is that the formation of the electrically conductive layer is more stable than other types of tools, such as copper. This is because the formation of this layer is influenced by components from the machining zone, such as carbon from the dielectric and the tool material. The physical and mechanical properties of isotropic graphite and zirconium oxide are shown in Table 1. Before conducting the experiments, all tools were surface ground to ensure normality with the workpiece. 
Table 1

Tool and workpiece properties

\begin{tabular}{|llll|}
\hline $\begin{array}{l}\text { Tool } \\
\text { Graphite TTK50 }\end{array}$ & $\begin{array}{l}\text { Workpiece } \\
\mathrm{ZrO}_{2}\end{array}$ & \\
\hline Density $\left[\mathrm{g} / \mathrm{cm}^{3}\right]$ & 1.80 & Density $\left[\mathrm{g} / \mathrm{cm}^{3}\right]$ & 5.68 \\
\hline Hardness [shore] & 70 & Melting point $\left[{ }^{\circ} \mathrm{C}\right]$ & 2720 \\
\hline Electrical Resistivity $[\mu \Omega \mathrm{m}]$ & 13 & Thermal Conductivity $[\mathrm{W} / \mathrm{m} \cdot \mathrm{K}]$ & 2 \\
\hline Flexural Strength $[\mathrm{MPa}]$ & 60 & Specific heat $\left[\mathrm{J} / \mathrm{Kg} \cdot{ }^{\circ} \mathrm{C}\right]$ & 400 \\
\hline Average particle Size $[\mu \mathrm{m}]$ & 6 & Electrical Resistivity $[\mu \Omega \mathrm{m}]$ & 1010 \\
\hline
\end{tabular}

For AEEDM of non-conducting materials to be possible, a hydrocarbon-based dielectric must be used. By converting electrical energy to thermal energy, the resulting high temperature visibly affects the dielectric in the discharge channel zone. In the absence of oxygen in the spark region, the high temperature causes thermochemical decomposition of the dielectric. The decomposition of a substance under the influence of high temperature, without the influence of other means, is called pyrolysis. As a result of the hydrolysis-induced pyrolysis of the dielectric, a carbon layer (pyrolytic layer) is formed. The resulting carbon layer corresponds to the melt layer formed during metalworking EDM and is structurally similar to graphite, which makes it electrically conductive.

Therefore, commercial mineral oil (Castrol llocut 180) with a flash point of $100^{\circ} \mathrm{C}$ was used as the dielectric fluid in this study. Natural graphite powder (Asbury PM19) and surfactant (Tween 20 $\mathrm{C} 58 \mathrm{H} 114026)$ are suspended in the dielectric oil. The powder material used was $95.5 \%$ pure graphite with an average particle size of $19 \mu \mathrm{m}$. The additive Tween 20 is added to the dielectric for better circulation in the discharge gap and to avoid particle agglomeration. A processing tank with a capacity of 20 litres was constructed to circulate the dielectric, Fig. 3, and a small pump and stirrer were also used to prevent the particles from sinking. To ensure homogeneous mixing of the medium, a stirrer set at $500 \mathrm{rpm}$ and a side flush of 0.5 bar were used during processing.

Various metal foils can be used as assisting electrodes. The most common are metal foils of aluminum and copper, which are mechanically applied to ceramic surfaces. The main advantage of this method is simplicity [19]. The main disadvantage of clamping metal foils onto ceramics is the lack of solid contact between metal and ceramics. Due to the lack of direct contact between the foil and the ceramics, the formation of the carbon layer is difficult, which leads to the instability of the AEEDM process, i.e., the interruption of the machining [20]. The combination of metal foil and graphite coating is called hybrid assisting electrode [21]. The metal foil provides the robustness i.e. strength of the assisting electrode, while the graphite coating acts adhesively between the metal foil and the ceramic. 
In this study, the workpiece material was a nonconductive ceramic. Therefore, for the application of EDM to process insulating ceramic material, a basic technique was developed in which a graphite layer (Graphite 33 lacquer) and an adhesive layer of copper foil (3M grade 1181) were applied to the workpiece surface, Fig. 4. First, the graphite layer was applied to the surface of the zirconia ceramic. Then, the workpiece was heated in an oven at $200^{\circ} \mathrm{C}$ for 2 hours. After heating, the carbon layer became conductive (resistance of $200 \Omega \mu \mathrm{m}$ ) and served as the first layer of $A E$ [22]. Then, the copper foil is placed on the graphite layer. In this case, the carbon layer is brittle and when the EDM process is carried out at higher energies, the carbon coating also often peels off in undesirable places [22]. Therefore, the surface is coated with an adherent copper layer which to provide robustness and prevent the AE from peeling off at undesirable locations. This additional electrically conductive layer is called a hybrid assisting electrode (HAE) [23].

\subsection{Machining conditions - preliminary experiments}

Based on the research $[24 ; 25]$, the main input parameters are discharge current, pulse duration, pulse off time, open voltage and polarity. Discharge current is the most commonly considered parameter in EDM of insulating ceramics [6]. According to the previous studies in the field of AEEDM, discharge currents up to 6 A have been used for tool cross sections up to $1 \mathrm{~cm}^{2}[7 ; 26]$.

Accordingly, a preliminary test was performed at 3.2 A. In this case, the eroded surface was obtained with a large surface roughness that could not be measured, Fig. 5 . Therefore, the discharge current up to $2 \mathrm{~A}$ is used for this investigation.

In the AEEDM of $\mathrm{ZrO}_{2}$, the electrical discharges in the machining gap between the tool electrode and the ceramic workpiece could not be established at an open voltage of $100 \mathrm{~V}$. This phenomenon occurred because the discharge energy in the process was too low to produce an effective carbon layer. With an auxiliary current of $0.5 \mathrm{~A}$, and a high voltage of $300 \mathrm{~V}$, the machining of insulating ceramics was made possible on machine SPU-1.

The pulse duration has a significant effect on the machining performance. The range of pulse duration was also selected based on preliminary experiments. As shown in Fig. 6 , it can be seen that the machining performance deteriorates as the pulse duration increases. The pulse on time was between 40 $\mu$ s and $100 \mu \mathrm{s}$, and the duty cycle $\tau$ was constant $50 \%$. Based on the literature for AEEDM of insulating ceramics, the duty cycle is between 20 and $50 \%$.

Some experiments were performed to verify the effectiveness of powder concentration. The input machining parameters were kept at constant values as shown in Fig. 7, and the powder concentration was varied from 0 to $8 \mathrm{~g} / \mathrm{l}$. When machining zirconia ceramics using the developed technique (AE + PM) EDM, it is obvious that the addition of a graphite powder into the dielectric produces better output machining performance. Preliminary experiments showed that surface roughness and tool wear rate 
increase with concentration above $4 \mathrm{~g} / \mathrm{l}$ of graphite powder. Therefore, $8 \mathrm{~g} / \mathrm{l}$ was adopted as the upper concentration limit.

\subsection{Machining performance}

The machining performance characteristics selected for this study were surface roughness $\left(R_{a}\right)$, material removal rate $(M R R)$ and tool wear ratio (TWR). The surface roughness measurements for the eroded surface were carried out using Perthometer, Mahr Surf PS1. The average surface roughness $R_{a}[\mu \mathrm{m}]$ was used to quantitatively assess the quality of the machine surface. In order to achieve the highest possible accuracy, the surface roughness tests were repeated three times for each test point and the average value was taken to obtain the surface roughness value.

The erosion depth of a workpiece is measured directly from a display of the machine (resolution of 1 $[\mu \mathrm{m}])$ and checked manually with a comparator. The material removal rate is expressed in cubic millimeters per minute $\left(\mathrm{mm}^{3} / \mathrm{min}\right)$ and refers to the machining efficiency of the EDM process and is defined as Eq. 1.

$$
M R R=\frac{\text { cross section electrode }\left(\mathrm{mm}^{2}\right) \times \text { depthofcut }(\mathrm{mm})}{\text { time of machining }(\mathrm{min})}\left[\frac{\mathrm{mm}^{3}}{\mathrm{~min}}\right]
$$

1

Tool wear can be expressed as a percentage of the original effective length of the electrode. The measured final wear is divided by the depth of the machined cut in the workpiece. Multiplying this number by 100 gives the percent wear ratio, Eq. 2. Accurate quantification of the tool wear ratio was possible with a precise length Abbe microscope resolution of $1[\mu \mathrm{m}]$. The reason for using this method is that the graphite tools may absorb a certain amount of the dielectric during the EDM process due to their porosity [27]. Therefore, it is difficult to determine the tool wear rate by a loss mass of the electrode.

$$
T W R=\frac{\text { Start lenght }- \text { final lenght }(\mathrm{mm})}{\text { Eroded depth }(\mathrm{mm})} \cdot 100 \quad[\%]
$$

2

\section{Experimental Setup And Design}

To study the effects of input parameters on machining performances, Box-Behnken Design (BBD) is used. The BBD is a rotatable design based on three-stage incomplete factorial designs [28], which has the advantage of requiring a smaller number of runs. This experimental design is more economical compared to other three-stage experimental designs due to the smaller number of experimental runs and 
allows the effects of input parameters on machining performance to be analyzed with a minimum number of trials [29].

The detailed machining conditions performed in this investigation, or the electrical and nonelectrical parameters of EDM, are given in Tables 2 and 3. The ranges of input parameters were selected based on preliminary tests, literature and machine limitations.

Table 2

Machining conditions

\begin{tabular}{|llll|}
\hline Parameters & Symbol & Value & Unit \\
\hline Discharge current & $I_{e}$ & $1 \div 2$ & $\mathrm{~A}$ \\
\hline Pulse on time & $t_{i}$ & $42 \div 100$ & $\mu \mathrm{s}$ \\
\hline Pulse off time & $t_{O}$ & $42 \div 100$ & $\mu \mathrm{s}$ \\
\hline Open circuit voltage & $U_{O}$ & 300 & $\mathrm{~V}$ \\
\hline High tension current & $I_{H}$ & 0.5 & $\mathrm{~A}$ \\
\hline Polarity & $P o l$ & $(-)$ & $/$ \\
\hline Duty factor & $\tau$ & 50 & $\%$ \\
\hline
\end{tabular}

Table 3

Non electrical parameters

\begin{tabular}{|c|c|c|c|c|}
\hline \multicolumn{2}{|c|}{$\begin{array}{l}\text { Non electrical } \\
\text { value }\end{array}$} & Symbol & Value & Unit \\
\hline \multirow[t]{4}{*}{$\mathrm{AE}$} & Copper & $3 M$ grade & $\approx 0.66$ & $\mathrm{~mm}$ \\
\hline & foil & 1181 & & \\
\hline & Graphite & Graphite 33 & $\approx 20$ & $\mu \mathrm{m}$ \\
\hline & lacquer & & & \\
\hline \multicolumn{2}{|c|}{ Retract distance } & $U P$ & 1.5 & $\mathrm{~mm}$ \\
\hline \multicolumn{2}{|c|}{ Erosion time } & $D N$ & 2 & s \\
\hline \multicolumn{2}{|c|}{ Graphite powder } & $G R$ & $0 \div 8$ & $g / l$ \\
\hline \multicolumn{2}{|c|}{ Surfactant } & $S R$ & 10 & $g / l$ \\
\hline \multicolumn{2}{|c|}{ Dielectric flow } & $Q$ & 20 & $1 / \min$ \\
\hline \multicolumn{2}{|c|}{ Machining time } & $T$ & 60 & $\min$ \\
\hline
\end{tabular}


The objective of this study is to determine the empirical formulas of $R_{a}, M R R$ and $T W R$ for (AE + PM) EDM. In the present study, only discharge current le, pulse on-time ti and $C$ are considered as processing parameters as design factors for (AE + PM) EDM of ZrO2 insulating ceramics, Table 4. A commercially available software package (Design-Expert) for experiment design and analysis was used to design the experiment.

Table 4

Experimental design matrix and collected data

\begin{tabular}{|c|c|c|c|c|c|c|c|c|c|c|}
\hline \multirow[t]{3}{*}{ No. } & \multicolumn{4}{|c|}{ Code factors } & \multicolumn{3}{|c|}{ Input parameters } & \multicolumn{3}{|c|}{ Machining performanse } \\
\hline & $x_{0}$ & $x_{1}$ & $x_{2}$ & $x_{3}$ & $\mathrm{I}_{\mathbf{e}}$ & $t_{i}$ & C & $\mathbf{R}_{\mathbf{a}}$ & & \\
\hline & & & & & (A) & ( $\mu s)$ & $g / l$ & $(\mu \mathrm{m})$ & $\left(\mathrm{mm}^{3} / \mathrm{min}\right)$ & (\%) \\
\hline 1. & 1 & -1 & -1 & 0 & 1 & 42 & 4 & 5.89 & 0.98 & 81.25 \\
\hline 2. & 1 & 1 & -1 & 0 & 2 & 42 & 4 & 8.99 & 2.02 & 53.21 \\
\hline 3. & 1 & -1 & 1 & 0 & 1 & 100 & 4 & 7.83 & 1.12 & 96.78 \\
\hline 4. & 1 & 1 & 1 & 0 & 2 & 100 & 4 & 12.74 & 2.61 & 58.65 \\
\hline 5. & 1 & -1 & 0 & -1 & 1 & 75 & 0 & 7.75 & 0.95 & 90.05 \\
\hline 6. & 1 & 1 & 0 & -1 & 2 & 75 & 0 & 14.96 & 2.23 & 59.22 \\
\hline 7. & 1 & -1 & 0 & 1 & 1 & 75 & 8 & 7.75 & 1.01 & 79.56 \\
\hline 8. & 1 & 1 & 0 & 1 & 2 & 75 & 8 & 12.85 & 2.59 & 58.44 \\
\hline 9. & 1 & 0 & -1 & -1 & 1.5 & 42 & 0 & 9.04 & 1.12 & 66.25 \\
\hline 10. & 1 & 0 & 1 & -1 & 1.5 & 100 & 0 & 12.89 & 1.25 & 77.58 \\
\hline 11. & 1 & 0 & -1 & 1 & 1.5 & 42 & 8 & 9.21 & 1.36 & 62.25 \\
\hline 12. & 1 & 0 & 1 & 1 & 1.5 & 100 & 8 & 10.55 & 1.42 & 72.65 \\
\hline 13. & 1 & 0 & 0 & 0 & 1.5 & 75 & 4 & 8.21 & 1.38 & 64.74 \\
\hline 14. & 1 & 0 & 0 & 0 & 1.5 & 75 & 4 & 8.61 & 1.39 & 62.44 \\
\hline 15. & 1 & 0 & 0 & 0 & 1.5 & 75 & 4 & 9.02 & 1.42 & 63.11 \\
\hline 16. & 1 & 0 & 0 & 0 & 1.5 & 75 & 4 & 8.88 & 1.31 & 62.99 \\
\hline 17. & 1 & 0 & 0 & 0 & 1.5 & 75 & 4 & 8.62 & 1.38 & 61.51 \\
\hline
\end{tabular}

\section{Results And Discussion}

RSM is a useful method for modeling and predicting the reactions affected by the input parameters with the aim of optimizing the reactions [30]. Therefore, this method is implemented to build mathematical 
models for each output processing power in terms of discharge current, pulse duration and powder concentration to express the predicted surface roughness, material removal volume and tool wear rate. As mentioned earlier, a series of 17 tests were performed according to the BBD. All machining parameters and measured output power with respect to each test are shown in Table 4.

There are four types of models that can be used in response modeling such as linear, two-factor interaction (2FI), quadratic and cubic polynomials for response. To examine the adequacy of the models for the responses, the method of analysis of variance (ANOVA) is performed. For each model, the probability is tested ("Prob F") to see if it falls below 0.05 . The fitting summary recommended that the quadratic models are statistically adequate for the analysis of $R_{a}, M R R$ and $T W R$.

\subsection{Surface roughness}

After fit summary, a quadratic model for surface roughness was proposed. To test the significance of the terms, analysis of variance was performed, which is mainly used to determine the p-value. It is known that $p$-value 0.05 or 0.1 indicates that the modal terms are significant. Using 10 levels of significance, a model is considered significant if the $p$-value is less than 0.1 . The non-significant terms were then removed using a backward elimination procedure. Table 5 shows the analysis of variance for the reduced quadratic model for estimating surface roughness after excluding the non-significant terms. The F-value of the proposed model is 38.68 , indicating that the model is highly significant at $0.04 \%$ probability level. 
Table 5

ANOVA for $R_{a}$ Reduced Quadratic Model

\begin{tabular}{|lllllll|}
\hline Source & Sum of & $\boldsymbol{d f}$ & $\begin{array}{l}\text { Mean } \\
\text { Squares }\end{array}$ & \multicolumn{5}{c|}{$\boldsymbol{F}$} & p-value & Contribution\% \\
& Value & & \\
\hline Model & 87.28 & 7 & 12.47 & 38.68 & $<0.0001$ & 55.08 \\
A-le & 49.68 & 1 & 49.68 & 154.08 & $<0.0001$ & 16.42 \\
B-ti & 14.81 & 1 & 14.81 & 45.93 & $<0.0001$ & 2.15 \\
C-GR & 1.94 & 1 & 1.94 & 6.03 & 0.0364 & 1.21 \\
AB & 1.09 & 1 & 1.09 & 3.39 & 0.0989 & 1.23 \\
AC & 1.11 & 1 & 1.11 & 3.44 & 0.0968 & 1.72 \\
BC & 1.55 & 1 & 1.55 & 4.80 & 0.0562 & 16.62 \\
$C^{2}$ & 14.99 & 1 & 14.99 & 46.48 & $<0.0001$ & 3.22 \\
Residual & 2.90 & 9 & 0.32 & 5.12 & 0.0694 & \\
Lack of Fit & 2.51 & 5 & 0.50 & & & \\
Pure Error & 0.39 & 4 & 0.098 & & & \\
Cor Total & 90.19 & 16 & & & & \\
\hline
\end{tabular}

According to Table 6, the values of $R^{2}$ and Adj. $R^{2}$ are 0.9678 and 0.9428 , while Pred. $R^{2}$ is 0.8161 , which are close to 1 . These statistical parameters called coefficient of determination indicate how well a regression model predicts responses for new observations. Results higher than 0.7 usually indicate that the predicted values follow the actual values. The AdEq. Precision of 23.330 implies a reasonable signal. This parameter measures the ratio of signal to noise, and a ratio greater than 4 is desirable.

Table 6

\begin{tabular}{|lcll|}
\multicolumn{4}{l}{ Basic statistical data of the adopted model for $R_{a}$} \\
\hline Std. Dev. & 0.57 & R-Squared & 0.9678 \\
Mean & 9.64 & Adj R-Squared & 0.9428 \\
C.V.\% & 5.89 & Pred R-Squared & 0.8161 \\
PRESS & 16.59 & Adeq Precision & 23.330 \\
\hline
\end{tabular}

The results of ANOVA show that the surface roughness is influenced by all input parameters. Finally, the model was constructed based on the remaining terms according to Table 6 . The mathematical model for determining surface roughness is shown in the decoded form, Eq. 3. 


$$
\begin{aligned}
R_{a} & =0.93019+3.51369 \cdot \mathrm{Ie}+0.014234 \cdot \mathrm{ti}-0.29084 \cdot \mathrm{GR}+0.035860 \cdot \mathrm{Ie} \cdot \mathrm{ti}- \\
& -0.26312 \cdot \mathrm{Ie} \cdot \mathrm{GR}-0.000535 \cdot \mathrm{ti} \cdot \mathrm{GR}+0.11757 \cdot G R^{2}
\end{aligned}
$$

Figure 8 shows the normal probability plot of the residuals for $R_{a}$. This plot compares a data set with the normal distribution. The plot of the theoretical percentiles of the normal distribution versus the observed percentiles of the sample is approximately linear. This shows that the model is good.

The effect of the input parameters on the surface roughness is shown in Fig. 9. As can be seen, the surface roughness of the insulating ceramic is low at low discharge current and low pulse duration, and the surface roughness is high at high values of these input parameters. This is because higher discharge energy directly increases the thermal energy in the discharge zone and the high discharge current and pulse duration results in increasing discharge energy of the single pulse, which in turn results in large surface roughness. Minimum surface roughness can be expected with the following processing parameters: discharge current of $1 \mathrm{~A}$, pulse duration of $42 \mu \mathrm{s}$ and concentration of graphite powder of 4 $\mathrm{g} / \mathrm{l}$.

\subsection{Material removal rate}

The quadratic model between the input parameters and the time chip volume is proposed and developed based on the RSM. Table 7 shows that the p-value of the model is 0.01 and F-value is 113.92, which means that the model is strongly significant at $99 \%$ confidence level for its adequacy. The $p$-values for $A$, $B, C, A B, A C$ and $A^{2}$ are 0.1 which expresses that these terms are significant. 
Table 7

ANOVA for MRR Quadratic Model

\begin{tabular}{|c|c|c|c|c|c|c|}
\hline Source & $\begin{array}{l}\text { Sum of } \\
\text { Squares }\end{array}$ & $d f$ & $\begin{array}{l}\text { Mean } \\
\text { Square }\end{array}$ & $\begin{array}{l}F \\
\text { Value }\end{array}$ & $\begin{array}{l}p \text {-value } \\
\text { Prob }>F\end{array}$ & significant \\
\hline Model & 4.47 & 6 & 0.74 & 113.92 & $<0.0001$ & \\
\hline A-le & 3.53 & 1 & 3.53 & 540.88 & $<0.0001$ & \\
\hline$B-t i$ & 0.11 & 1 & 0.11 & 17.36 & 0.0019 & \\
\hline$C-G R$ & 0.084 & 1 & 0.084 & 12.90 & 0.0049 & \\
\hline$A B$ & 0.060 & 1 & 0.060 & 9.13 & 0.0129 & \\
\hline$A C$ & 0.025 & 1 & 0.025 & 3.87 & 0.0775 & \\
\hline$A^{2}$ & 0.53 & 1 & 0.53 & 80.92 & $<0.0001$ & \\
\hline Residual & 0.065 & 10 & $6.533 E-003$ & 5.47 & 0.0610 & \\
\hline Lack of Fit & 0.058 & 6 & $9.706 E-003$ & & & \\
\hline Pure Error & 7.100E-003 & 4 & $1.775 E-003$ & & & \\
\hline Cor Total & 4.53 & 16 & & & & not significant \\
\hline
\end{tabular}

Table 8 shows basic statistics of the assumed model for MRR. The values of $\mathrm{R}^{2}$ and Adj. $\mathrm{R}^{2}$ are 0.9856 and 0.9769 , respectively, which are close to 1 . Moreover, the AdEq. Precision of 30.829 is greater than 4, which implies an adequate signal. Therefore, the developed model can navigate the material removal rate.

Table 8

Basic statistical data of the adopted model for $M R R$

\begin{tabular}{|lcll|}
\hline Std. Dev. & 0.081 & R-Squared & 0.9856 \\
Mean & 1.51 & Adj R-Squared & 0.9769 \\
C.V. \% & 5.37 & Pred R-Squared & 0.9421 \\
PRESS & 0.26 & Adeq Precision & 30.829 \\
\hline
\end{tabular}

The mathematical model is quite well fitted based on the previous analysis with the observed values. After eliminating the non-significant terms by backward elimination, the final mathematical Eq. 4 for the response in actual factors for $M R R$ is as follows: 


\section{$M R R=+3.24496-3.65821 \cdot \mathrm{Ie}-0.00805 \cdot \mathrm{ti}-0.033969 \cdot \mathrm{GR}+0.00807 \cdot \mathrm{Ie} \cdot \mathrm{ti}+$ $+0.039750 \cdot I e \cdot G R+1.41324 \cdot I e^{2}$}

A normal plot of residuals for the material removal rate is shown in Fig. 10. It can be seen that implying the residuals in the prediction of each response are negligible, i.e. the actual values have a strong agreement with the predicted values.

The effect of discharge current and pulse duration on $M R R$ is shown in Fig. 11. As can be seen from this figure, the $M R R$ tends to increase, considerably with increase in discharge current for any value of pulse duration. Hence, maximum MRR is obtained at high discharge current $2 \mathrm{~A}$, pulse duration $100 \mu \mathrm{s}$ and concentration graphite powder $4 \mathrm{~g} / \mathrm{l}$. This is because these parameters have dominant control over the input energy. This input energy generates heat which leads to high temperature, resulting in local melting, evaporation and dissociation (spalling) of workpiece material.

\subsection{Tool wear rate}

The fit summary statistics suggested that the quadratic model is significant for the analysis of TWR. The results of the quadratic model for TWR, in the form of ANOVA, after elimination of non-significant terms are given in Table 9. It is clear that the F-value of the model is 113.92, which indicate that the model is significant with a probability of $0.01 \%$. The $p$ values of $A, B, C, A B, A C$, and $A^{2}$ are smaller than 0.1 , which expresses that those terms are significant for model. 
Table 9

Reduced ANOVA for TWR Quadratic Model

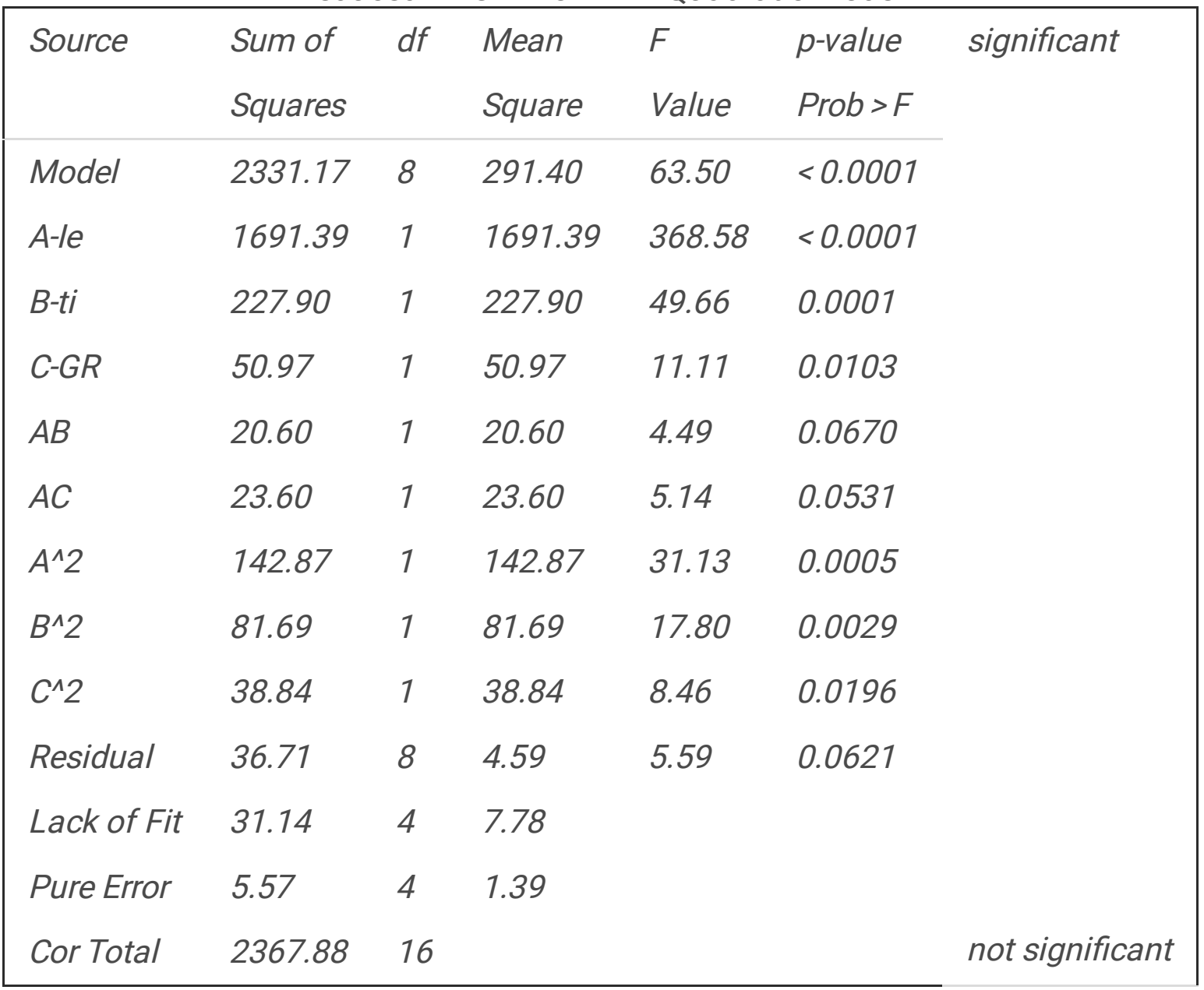

Basic statistical data of the adopted model for TWR are shown in Table 10. The value of $R$-Squared and Adjusted R-Squared is over $96 \%$, and the Pred R-Squared of 0.7909 , demonstrates agreement with coefficients of determination. Also, AdEq. Precision of 25.594 suggests an adequate signal. This means that the mathematical model gives a very good explanation of the relationship between the input factors and the tool wear rate.

Table 10

Basic statistical data of the adopted model for $T W R$

\begin{tabular}{|llll|}
\hline Std. Dev. & 2.14 & R-Squared & 0.9845 \\
Mean & 68.87 & Adj R-Squared & 0.9690 \\
C.V. \% & 3.11 & Pred R-Squared & 0.7909 \\
PRESS & 495.23 & Adeq Precision & 25.594 \\
\hline
\end{tabular}

As with previous models, the residual plot for TWR is shown in Fig. 12. It is visible the residuals are normally distributed. That means the errors are normally distributed, i.e., the actual and predicted values have a good agreement. The final response equation for TWR is given in Eq. 5. 


\section{$T W R=168.63046-92.91856 \cdot \mathrm{Ie}-0.34423 \cdot \mathrm{ti}-3.9714 \cdot \mathrm{GR}-0.15575 \cdot \mathrm{Ie} \cdot \mathrm{ti}+$ \\ $+1.21450 \cdot I e \cdot G R+23.30050 \cdot I e^{2}+0.00536 \cdot t i^{2}+0.18984 \cdot G R^{2}$}

To analyze the effect of (AE + PM) EDM parameters on $T W R$, response surface graph has been plotted as shown in Fig. 13. In machining parameters, such as discharge current $2 \mathrm{~A}$, pulse duration $42 \mu$ s and graphite powder concentration $4 \mathrm{~g} / \mathrm{l}$, minimal tool wear rate was obtained.

It is noticeable that an increase in the discharge current leads to a decrease in the tool wear rate. This is justified by the fact that at lower discharge currents more time is spent on removing the material of assisting electrode and forming the carbon layer, where the tool is most consumed. A limited experiment time of $60 \mathrm{~min}$ also contributes to this, where in some cases the time required to form the layer was approximately $30 \mathrm{~min}$. A similar conclusion emerged from a study by [6]. In that study, the tool wear rate was monitored through three phases: a) removal of the material of assisting electrode, $b$ ) formation of the transition layer, and c) removal of the base material. The highest relative tool wear was recorded in the first and second phases, while a significant reduction occurred in the third phase. Increasing the pulse duration also contributes to increasing the relative wear of the tool.

\subsection{Effect of powder concentration}

The space between the tool and the workpiece, i.e. the working gap, is filled with electrically conductive powder particles. Under the influence of voltage, a strong electromagnetic field is formed at the smallest local distance between the tool surface and the workpiece, i.e. at the point of least resistance to the passage of electric current. In the electric field, there is an intense accumulation of powder particles, which create a bridging effect, forming a kind of electrically conductive bridge, i.e. the so-called "zigzag" shape. The enhanced bridging effect reduces the discharge voltage and insulation properties of the dielectric. At the same time, the powder particles change the properties of the discharge channel, which equalizes the distribution of sparks on the powder particles and thus reduces the current density. Due to this uniform distribution of the discharge, there is uniform removal, i.e., shallow craters on the workpiece, which leads to a reduction in surface roughness, a reduction in tool wear, and thus an increase in machining accuracy. It is also found that with the increase of discharge current, the material removal rate of machining increases but the stability of machining process decreases because the higher intensity discharge current creates larger craters on the workpiece and directly affects the stability of the electrically conductive layer. The insulating properties of the dielectric are reduced, which leads to an increase in the working gap, resulting in more efficient flushing of the working space between the tool and the workpiece. This is especially marked in the case of the maximum pulse duration. For it is known that for each material pairing (tool - workpiece) there is a maximum pulse duration which must not be exceeded. Because in this case the material would be destroyed. This is because it is well known that surface roughness and material removal rate deteriorate with longer pulse duration. The presence of a concentration of graphite powder contributes to the formation of a carbon layer, which makes the (AE + PM) EDM process more stable. 
The improved machining performance achieved when the graphite powder is suspended on the dielectric is related to the reduction in surface roughness, material removal rate, and tool wear rate. The effect of graphite powder concentration on machining performance is shown in Fig. 14. The best effect of adding graphite powder was found at a discharge current of $1.5 \mathrm{~A}$ and a pulse duration of $100 \mu \mathrm{s}$. Here, the surface roughness was reduced by about $18 \%$ with an additional graphite powder concentration of $8 \mathrm{~g} / \mathrm{l}$, while the MRR increased by $12 \%$ and the TWR decreased by $6 \%$. This regime was not declared optimal, but it reflects the greatest influence of the addition of graphite powder.

\subsection{Models verification}

Table 4 provides a comparative view of the experimental and model values ( $E V$ and $M V$ ) for the machining performance in (AE + PM) EDM zirconium oxide. Quantitative predictability was estimated in relation to the percentage deviation between the obtained and expected values (Eq. 6) for $R_{a}, M R R$ and $T W R$, in other words through the relative error $R E$ :

$$
R E=\left|\frac{E V-M V}{E V}\right| * 100 \%
$$

Based on the calculation of the relative error of each point of the experiment, the average error of the observed models was calculated, Table 4. The developed models, based on the response surface methodology showed good agreement with the experimental data.

Verification of the accuracy of the obtained models was performed using three additional experiments that did not participate in the model generation process. Table 11 gives the additional experiments of (AE + PM) EDM zirconium oxide, as well as the results of the confirmatory test. Based on verification experiments, the average error of the obtained models ranges from $4.08 \div 8.74 \%$. According to previous research, a model is considered capable of prediction if the average error is approximately $10 \%$. In this context, all models for output performance prediction, obtained using the RSM can be considered capable of prediction because their percentage error is within the allowable limits. In order to increase the reliability of the obtained models, a larger amount of data is needed, which is used to create the model. 
Table 11

Models verification results

\begin{tabular}{|c|c|c|c|c|c|c|c|c|c|}
\hline \multirow[t]{4}{*}{ No. } & \multicolumn{3}{|c|}{ Input parameters } & \multicolumn{6}{|c|}{ Machining performance } \\
\hline & \multirow{3}{*}{$\begin{array}{l}I_{e} \\
\text { (A) }\end{array}$} & \multirow{3}{*}{$\begin{array}{l}t_{i} \\
(\mu \mathrm{s})\end{array}$} & \multirow{3}{*}{$\begin{array}{l}G R \\
(g / l)\end{array}$} & \multirow{2}{*}{\multicolumn{2}{|c|}{$\begin{array}{l}R_{a} \\
(\mu \mathrm{m})\end{array}$}} & \multirow{2}{*}{\multicolumn{2}{|c|}{$\begin{array}{l}M R R \\
\left(\mathrm{~mm}^{3} / \mathrm{min}\right)\end{array}$}} & \multirow{2}{*}{\multicolumn{2}{|c|}{$\begin{array}{l}\text { TWR } \\
\text { (\%) }\end{array}$}} \\
\hline & & & & & & & & & \\
\hline & & & & Exp. & RSM & Exp. & RSM & Exp. & RSM \\
\hline 1. & 1.5 & 75 & 0 & 10.201 & 11.297 & 1.307 & 1.216 & 70.547 & 68.521 \\
\hline 2. & 1.5 & 42 & 4 & 8.11 & 8.191 & 1.33 & 1.196 & 65.33 & 61.312 \\
\hline 3. & 2 & 75 & 0 & 14.47 & 14.398 & 1.99 & 2.175 & 56.11 & 56.996 \\
\hline \multicolumn{4}{|c|}{ Average error } & / & 4.08 & / & 8.74 & / & 3.53 \\
\hline
\end{tabular}

\section{Conclusions}

The paper presents the results of an experimental investigation carried out with the aim of modelling the electrical discharge machining of non-conductive ceramic material. By applying a graphite coating and placing an adhesive copper strip on the top of the workpiece, a hybrid assisting electrode was obtained, which is responsible for the successful electrical discharge machining of zirconia. The addition of graphite powder to the dielectric when machining zirconia in the presence of an assisting electrode results in an $18 \%$ reduction in surface roughness, a $12 \%$ increase in metal removal rate, and a $6 \%$ reduction in relative tool wear. These performance increases are achieved at a discharge current of $1.5 \mathrm{~A}$, a pulse length of $100 \mu \mathrm{s}$, and a graphite powder concentration of $8 \mathrm{~g} / \mathrm{l}$. The structural shapes of the mathematical models for the output power $R_{a}, M R R$ and $T W R$ were obtained using the response surface methodology according to the plan Box-Behnken. Based on the experiments that were not involved in obtaining the model, the verification of the model was carried out, i.e. the evaluation of the ability to predict the output power with new experimental data. The model error obtained by the verification experiments for (AE + PM) EDM zirconia $4.08 \%$ for $R_{a}, 8.74 \%$ for $M R R$ and $3.53 \%$ for $T W R$. In conclusion, it can be safely said that the research results presented in the paper provide a better understanding of $(A E+P M) E D M$, which will contribute to its greater competitiveness in the industry. Considering the fact that $(A E+P M) E D M$ are relatively new machining processes that have not been fully explored, there is certainly the possibility of their further continuous improvement and refinement.

\section{Declarations}

\section{Acknowledgment}

This paper has been supported by the Ministry of Education, Science and Technological Development through the project no. 451-03-68/2020-14/200156: "Innovative scientific and artistic research from the FTS (activity) domain". 


\section{Ethical Approval}

This paper does not contain any studies with human participants or animals performed by any of the authors.

\section{Consent to Participate}

Publication is approved by all co-authors, as well as by the responsible authorities at the Department of Production Engineering.

\section{Consent to Publish}

Our manuscript has not been previously published and is not under consideration for publication elsewhere. Paper represents original work.

\section{Authors Contributions}

D. Rodic and M. Gostimirovic conceived of the presented idea. D.R. developed the theory and performed the computations. D. Rodic and M. Gostimirovic verified the mathematical methods. M. Sekulic and B. Savkovic conceived and planned the experiments. B. Strbac assisted with all necessary measurements. All authors provided critical feedback and helped shape the research, analysis and manuscript.

\section{Funding}

This study was funded by the project no. 451-03-68/2020-14/200156.

\section{Competing Interests}

The authors declare that they have no conflict of interest.

\section{Availability of data and materials}

The data underlying this article are available in the article.

\section{Abbreviations}

\section{List of acronyms}

EDM - Electrical Discharge Machining

AE - Assisting Electrode

AEEDM - Assisting Electrode Electrical Discharge Machining $(A E+P M)$ EDM - Assisting Electrode Powder Mixed Electrical Discharge Machining 
$M R R$ - material removal rate

$T W R$ - tool wear rate

\section{Notations}

$R_{a}$ - surface roughness

$I_{e}-$ discharge current

$t_{i}-$ pulse duration

$U_{0}-$ voltage

$G R$ - concentration of graphite powder

\section{References}

1. Yang Z, Zhu L, Zhang G, Ni C, Lin B (2020) Review of ultrasonic vibration-assisted machining in advanced materials. Int J Mach Tool Manu:103594.

https://doi.org/10.1016/j.ijmachtools.2020.103594

2. Wang J, Fu C, Jia Z (2018) Cutting of hard and brittle insulating materials using spark dischargeassisted diamond wire sawing. J Mater Process Technol 252:225-232. https://doi.org/10.1016/j.jmatprotec.2017.09.027

3. Gostimirovic M, Radovanovic M, Madic M, Rodic D, Kulundzic N (2018) Inverse electro-thermal analysis of the material removal mechanism in electrical discharge machining. Int J Adv Manuf Technol 97(5-8):1861-1871. https://doi.org/10.1007/s00170-018-2074-y

4. Wang X, Yi S, Easton M, Ding S (2020) Active gap capacitance electrical discharge machining of polycrystalline diamond. J Mater Process Technol 280:116598. https://doi.org/10.1016/j.jmatprotec.2020.116598

5. König W, Dauw D, Levy G, Panten U (1988) EDM-future steps towards the machining of ceramics. CIRP Annals 37(2):623-631. https://doi.org/10.1016/S0007-8506(07)60759-8

6. Fukuzawa Y, Tani T, Iwane E, Mohri N (1995) A New Machining Method for Insulating Ceramics with an Electrical Discharge Phenomenon. J Ceram Soc Japan 103(10):1000-1008. https://doi.org/10.2109/jcersj.103.1000

7. Tani T, Fukuzawa Y, Kawase T, Futurani K, Mohri N, Saito N (1998) Machining Characteristics of ZrO2 Ceramics by Electrical Discharge Machining. J Japan Soc Elect Mach Eng 32(71):18-26. https://doi.org/10.2526/jseme.32.71_18

8. Mohri N, Fukusima Y, Fukuzawa Y, Tani T, Saito N (2003) Layer generation process on work-piece in electrical discharge machining. CIRP Annals 52(1):157-160. https://doi.org/10.1016/S00078506(07)60554-X 
9. Hanaoka D, Ito R, Fukuzawa Y (2011) Electrical discharge machined surface of the insulating ZrO2 ceramics. J Adv Mech Des Syst 5(4):372-384. https://doi.org/10.1299/jamdsm.5.372

10. Tani T, Fukuzawa Y, Mohri N, Saito N (1996) Effects of Assisting Electrode Material on the EDMed Characteristics for Insulating Sialon Ceramics. J Japan Soc Elect Mach Eng 30(65):17-23. https://doi.org/10.2526/jseme.30.65_17

11. Fukuzawa Y, Mohri N, Tani T, Muttamara A (2004) Electrical discharge machining properties of noble crystals. J Mater Process Technol 149(1-3):393-397. https://doi.org/10.1016/j.jmatprotec.2003.12.028

12. Renije J, Yonghong L, Yanzehn Z, Wang F, Baoping C, Xingsheng F (2012) Single discharge machining insulating $\mathrm{Al} 2 \mathrm{O} 3$ ceramic with high instantaneous pulse energy in kerosene. Mater Manuf Process 27(12):676-682. https://doi.org/10.1080/10426914.2011.602783

13. Sabur A, Ali MY, Malaque A, Khan AA (2013) Investigation of material removal characteristics in EDM of nonconductive ZrO2 ceramic. Procedia Eng 56:696-701. https://doi.org/10.1016/j.proeng.2013.03.180

14. Chen YF, Lin YJ, Chen SL, Lin YC, Hsu LR (2010) Optimization of electrodischarge machining parameters on $\mathrm{ZrO}_{2}$ ceramic using the Taguchi method. P I Mech Eng B-J Eng 224(2):195-205. https://doi.org/10.1243/09544054JEM1437

15. Tani T, Fukuzawa Y, Nanbu K, Mohri N (2002) Machining phenomena in EDM of insulating ceramics with powder mixed oil. J Japan Soc Elect Mach Eng 36(81):39-46. https://doi.org/10.2526/jseme.36.39

16. Sabur A, Mehdi SM, Ali MY, Maleque MA, Moudood MA (2015) Investigation of Surface Roughness in Micro-EDM of Nonconductive ZrO2 Ceramic with Powder Mixed Dielectric Fluid. Adv Mat Res 1115:16-19. https://doi.org/10.4028/www.scientific.net/AMR.1115.16

17. Kucukturk G, Cogun C (2010) A new method for machining of electrically nonconductive workpieces using electric discharge machining technique. Mach Sci Technol 14(2):189-207. https://doi.org/10.1080/10910344.2010.500497

18. Raju P, Babasaheb S (2021) Study on analysis of plasma resistance variation in WEDM of insulating zirconia. Mater Manuf Process 36(1):59-72. https://doi.org/10.1080/10426914.2020.1813898

19. Banu A, Ali MY, Abd Rahman M (2014) Micro-electro discharge machining of non-conductive zirconia ceramic: investigation of MRR and recast layer hardness. Int J Adv Manuf Technol 75(1-4):257-267. https://doi.org/10.1007/s00170-014-6124-9

20. Guo Y, Hou P, Shao D, Li Z, Wang L, Tang L (2014) High-speed wire electrical discharge machining of insulating zirconia with a novel assisting electrode. Mater Manuf Process 29(5):526-531. https://doi.org/10.1080/10426914.2014.892983

21. Sabur A, Ali MY, Maleque MA, Khan AA (2013) Investigation of material removal characteristics in EDM of nonconductive ZrO2 ceramic. Procedia Eng 56:696-701. https://doi.org/10.1016/j.proeng.2013.03.180 
22. Ojha $N$, Hosel T, Muller $C$, Reinecke $H$ (2013) Characterization of the conductive layer formed during $\mu$ - electric discharge machining of non-conductive ceramics. Processing and Properties of Advanced Ceramics and Composites V: Ceramic Transactions 240:105-110. https://doi.org/10.1002/9781118744109.ch12

23. Ojha N, Zeller F, Mueller C, Reinecke H (2015) Analyzing the electrical pulses occurring during EDM of non-conductive Si3N4 ceramics. Key Eng Mater 651-653:659-664. https://doi.org/10.4028/www.scientific.net/KEM.651-653.659

24. Mohri N, Saito N, Tsunekawa Y, Kinoshita N (1993) Metal surface modification by electrical discharge machining with composite electrode. CIRP annals 42(1):219-222. https://doi.org/10.1016/S00078506(07)62429-9

25. Klocke F, Holsten M, Hensgen L, Klink A (2014) Experimental investigations on sinking-EDM of seal slots in gamma-TiAl. Procedia CIRP 24:92-96. https://doi.org/10.1016/j.procir.2014.07.143

26. Gotoh H, Tani T, Mohri N (2016) EDM of Insulating Ceramics by Electrical Conductive Surface Layer Control. Procedia CIRP 42:201-205. https://doi.org/10.1016/j.procir.2016.02.271

27. Amorim FL, Weingaertner WL (2007) The behavior of graphite and copper electrodes on the finish die-sinking electrical discharge machining (EDM) of AISI P20 tool steel. Journal of the Brazilian Society of Mechanical Sciences and Engineering 29(4):366-371. https://doi.org/10.1590/S167858782007000400004

28. Ferreira SC, Bruns R, Ferreira H, et al. (2007) Box-Behnken design: an alternative for the optimization of analytical methods. Anal Chim Acta 597(2):179-186. https://doi.org/10.1016/j.aca.2007.07.011

29. Montgomery DC (2017) Design and analysis of experiments. John wiley \& sons

30. Xing Y, Liu L, Hao X, Wu Z, Huang P, Wang X (2018) Micro-channels machining on polycrystalline diamond by nanosecond laser. Opt Las Technol 108:333-345. ttps://doi.org/10.1016/j.optlastec.2018.07.024

\section{Figures}




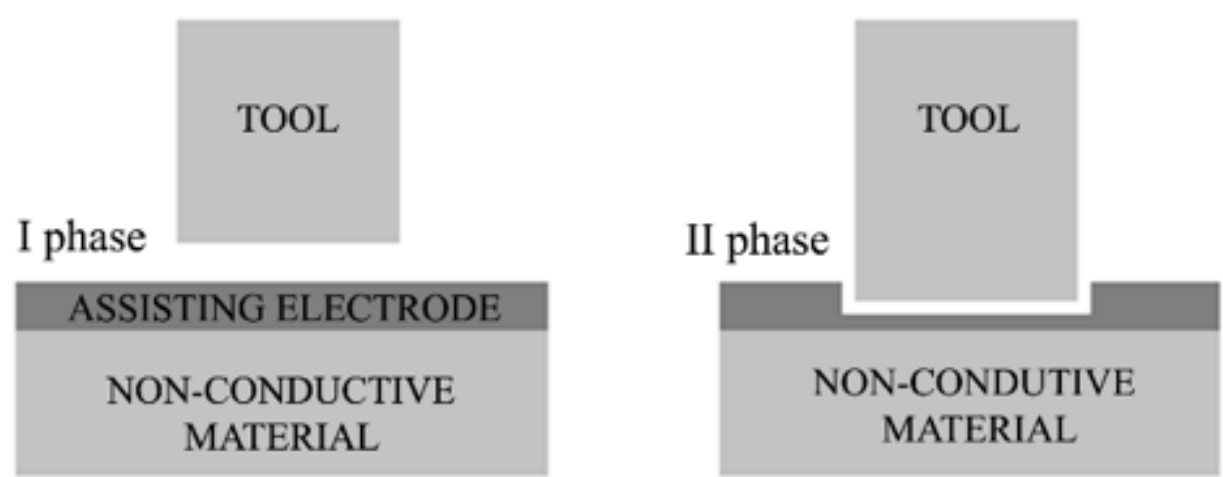

INITIAL ELECTRICAL DISCHARGE MACHINIG OF ASSISTING ELECTRODE

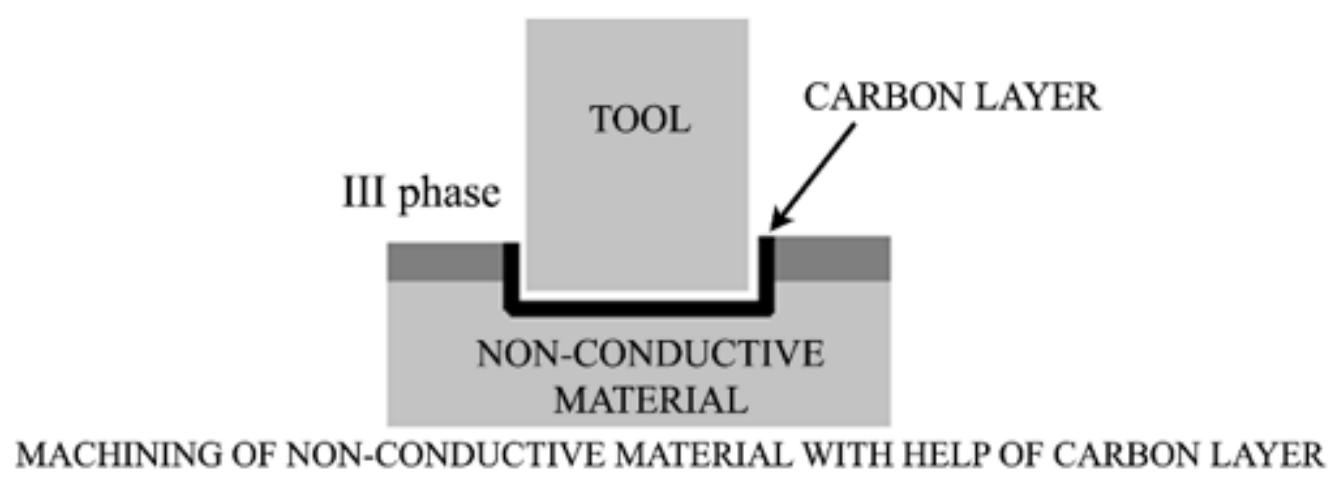

Figure 1

Schematic representation EDM of non-conductive material using assisting electrode 


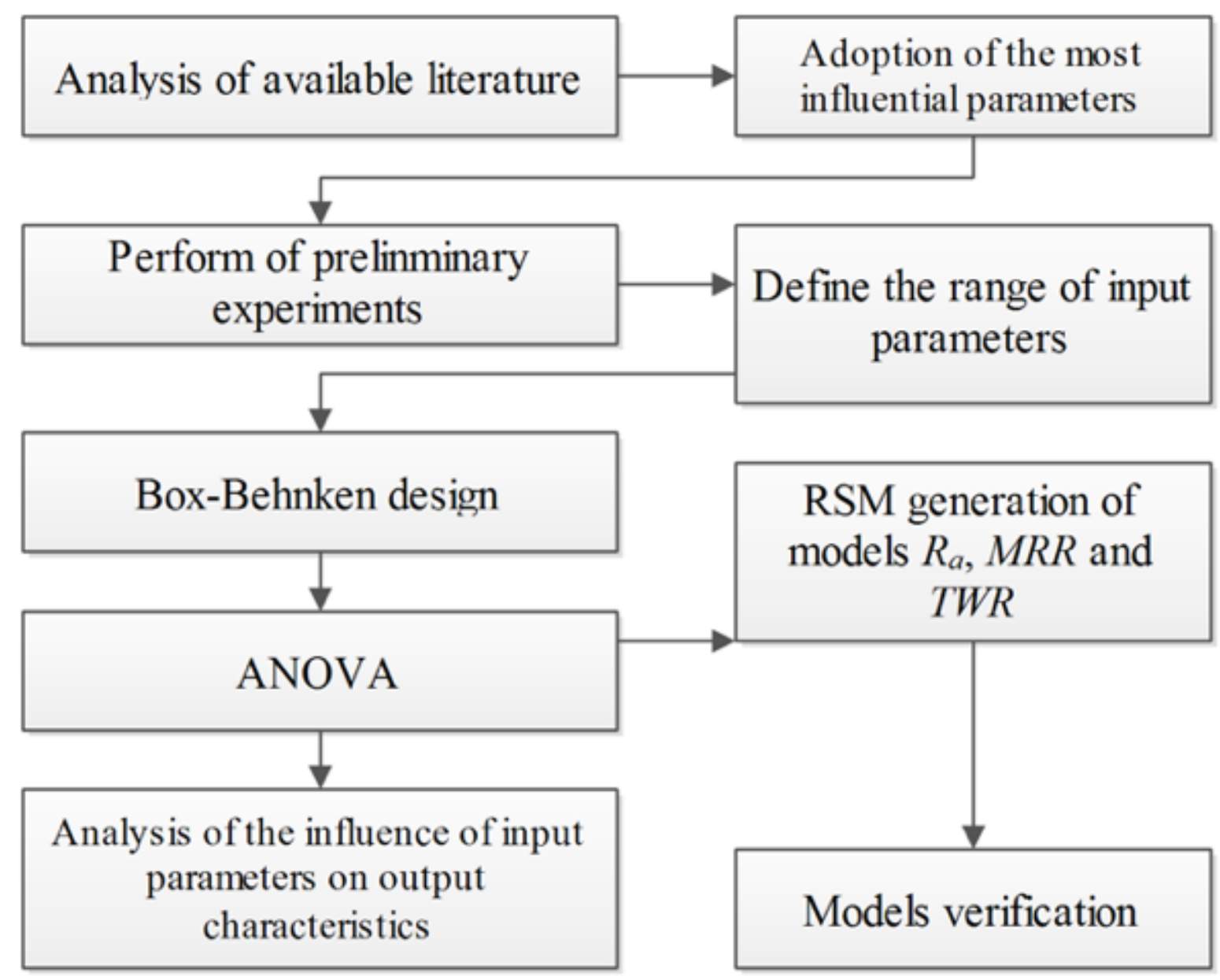

Figure 2

Flowchart of the research methodology 


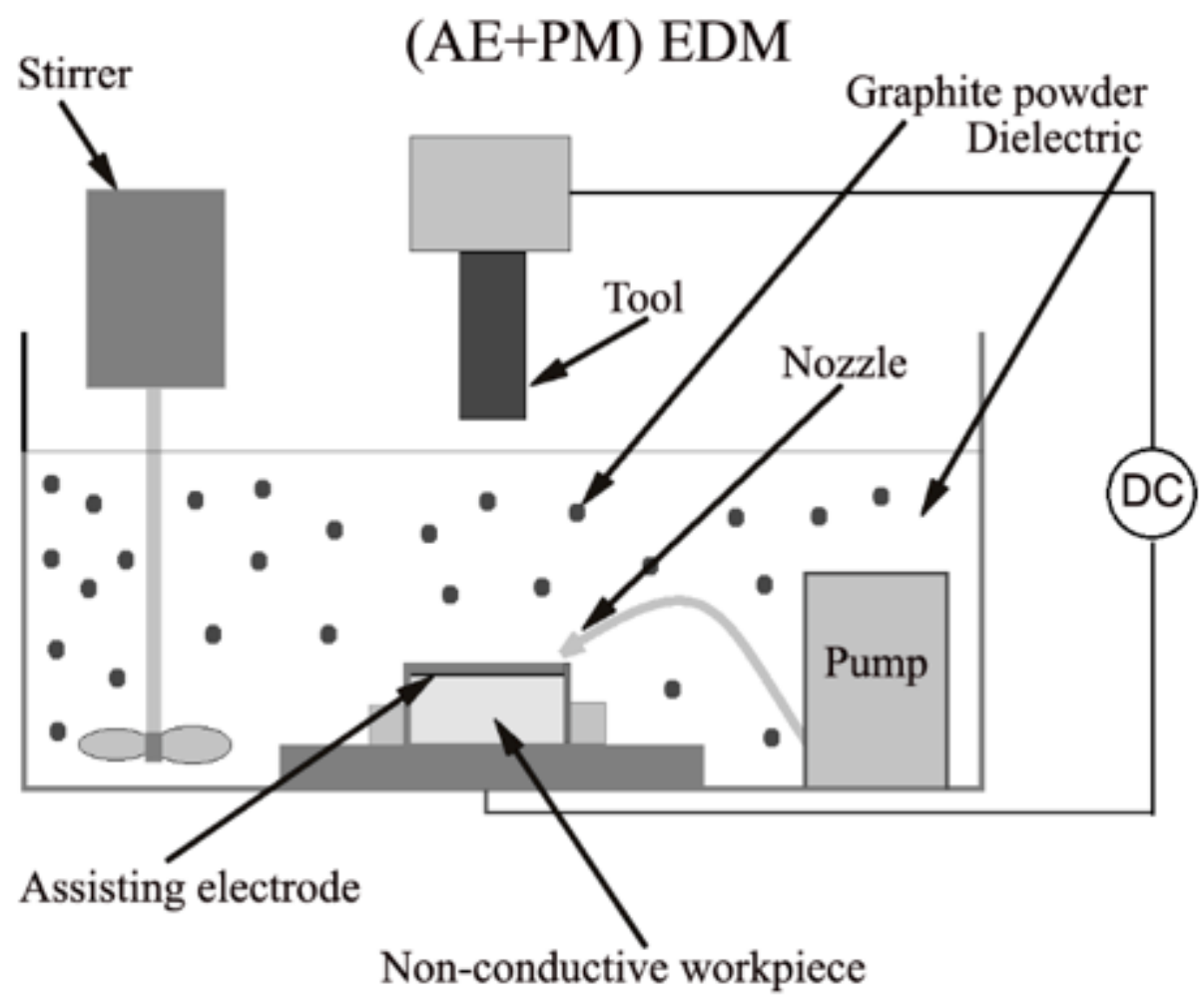

Figure 3

Assisting electrode powder mixed method (AE+PM) EDM

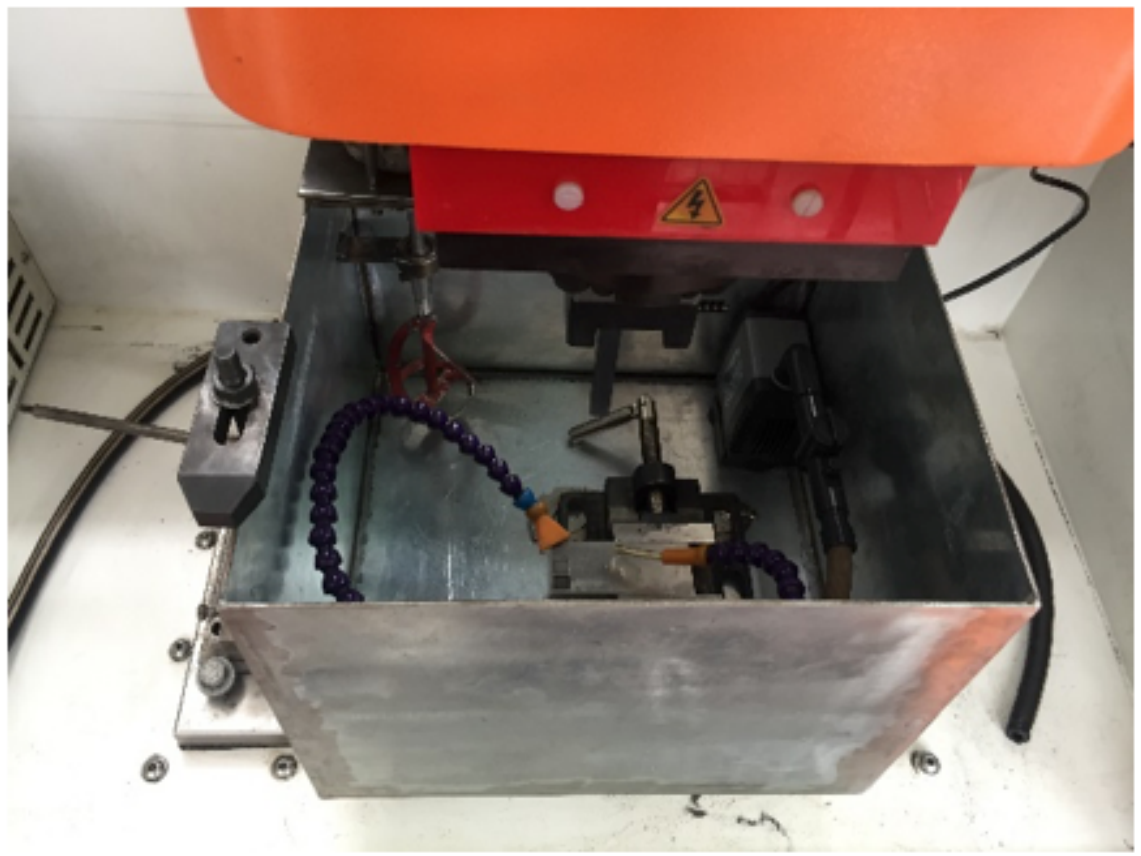

Figure 4

Powder mixed tank with stirrer and pump 


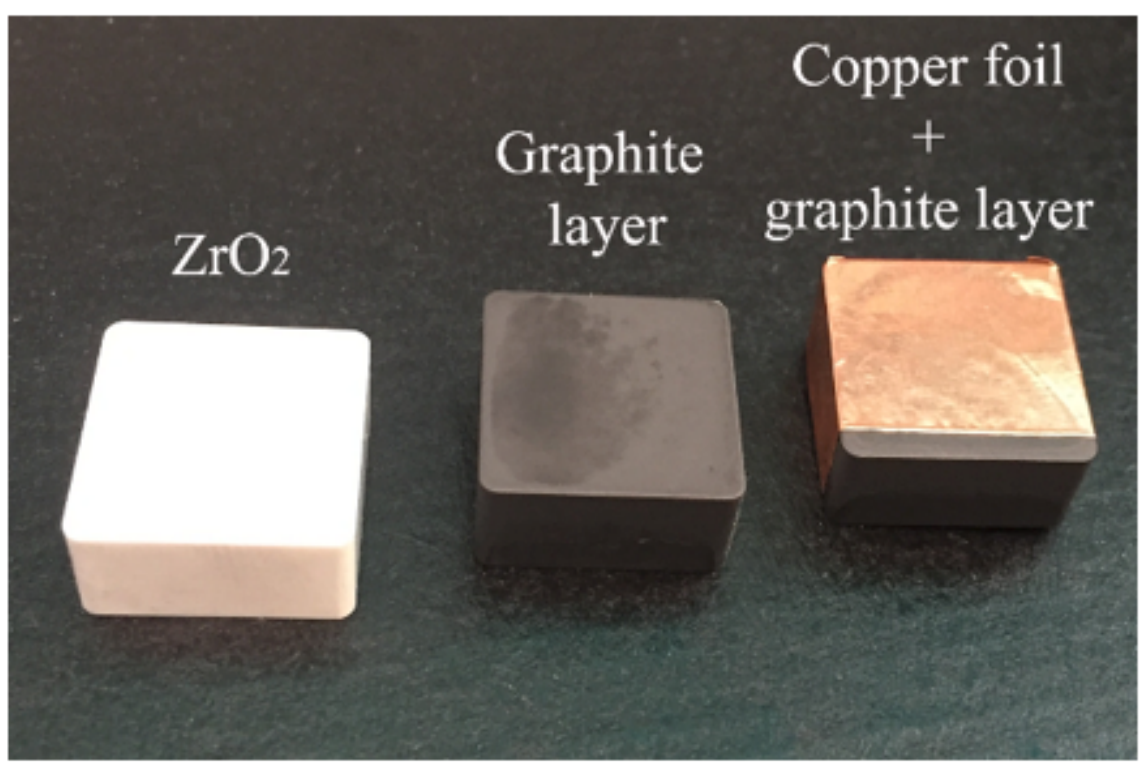

Figure 5

Hybrid assisting electrode

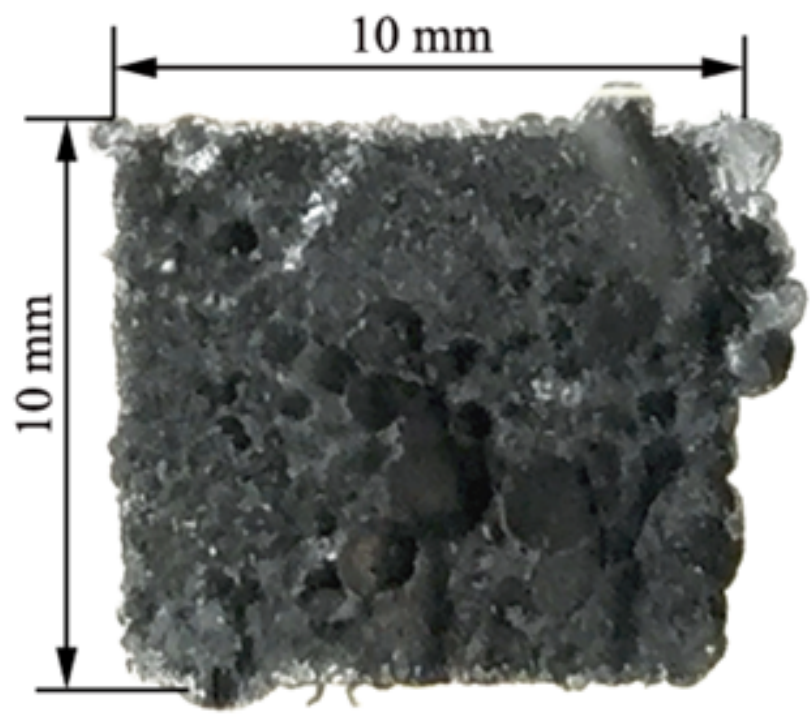

$I_{e}=3.2 \mathrm{~A}$

$t_{i}=75 \mu \mathrm{s}$

$\tau=50 \%$

$U_{o}=300 \mathrm{~V}$

$I_{H}=0.5 \mathrm{~A}$

Diel.:Ilocut 180

Tool: TTK50

Workpiece: $\mathrm{ZrO}_{2}$

Figure 6

The eroded surface after AEEDM 


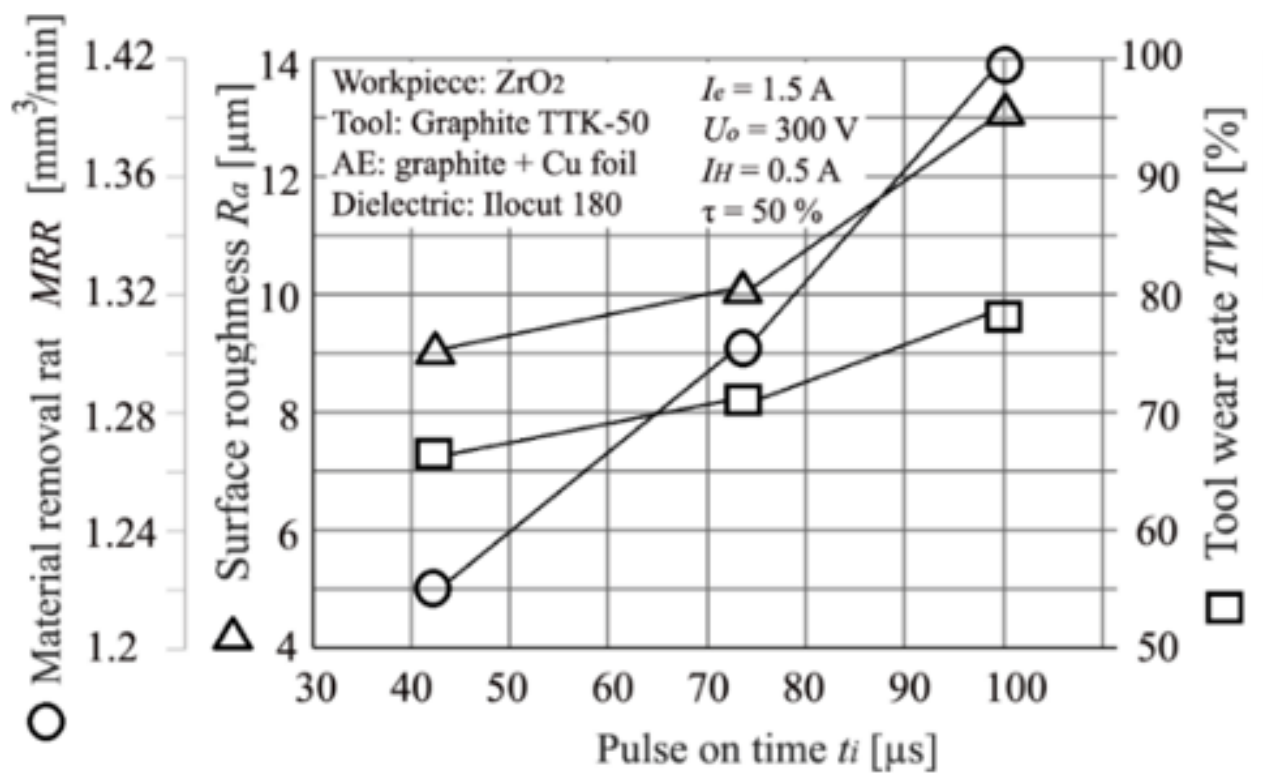

Figure 7

Influence pulse on time on machining performance

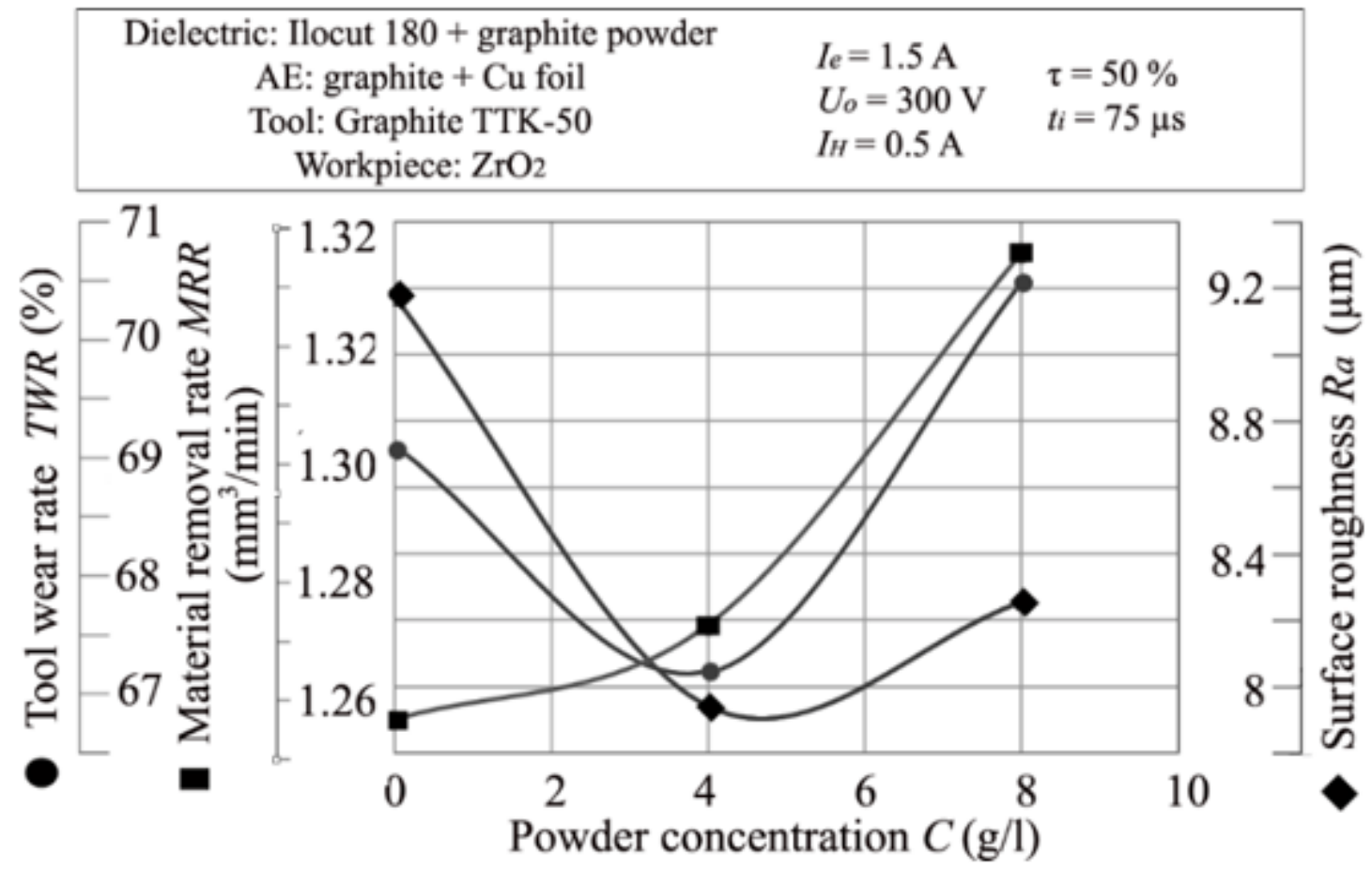

Figure 8

Influence powder concentration on machining performances 


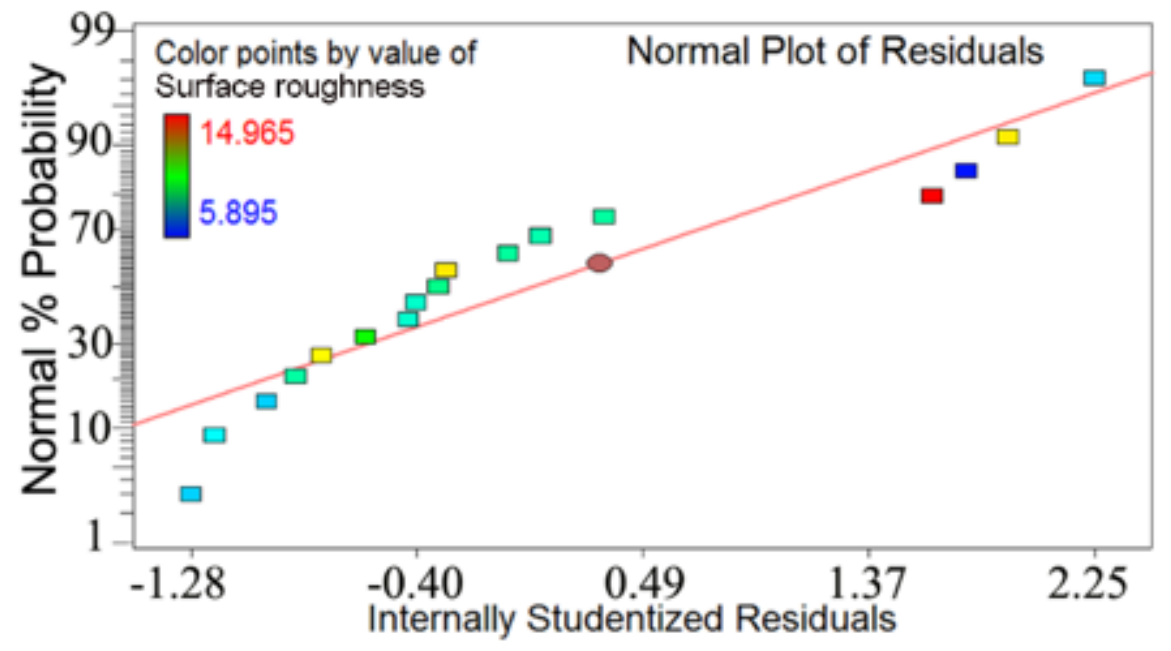

Figure 9

Normal plot of residual for $\mathrm{Ra}$

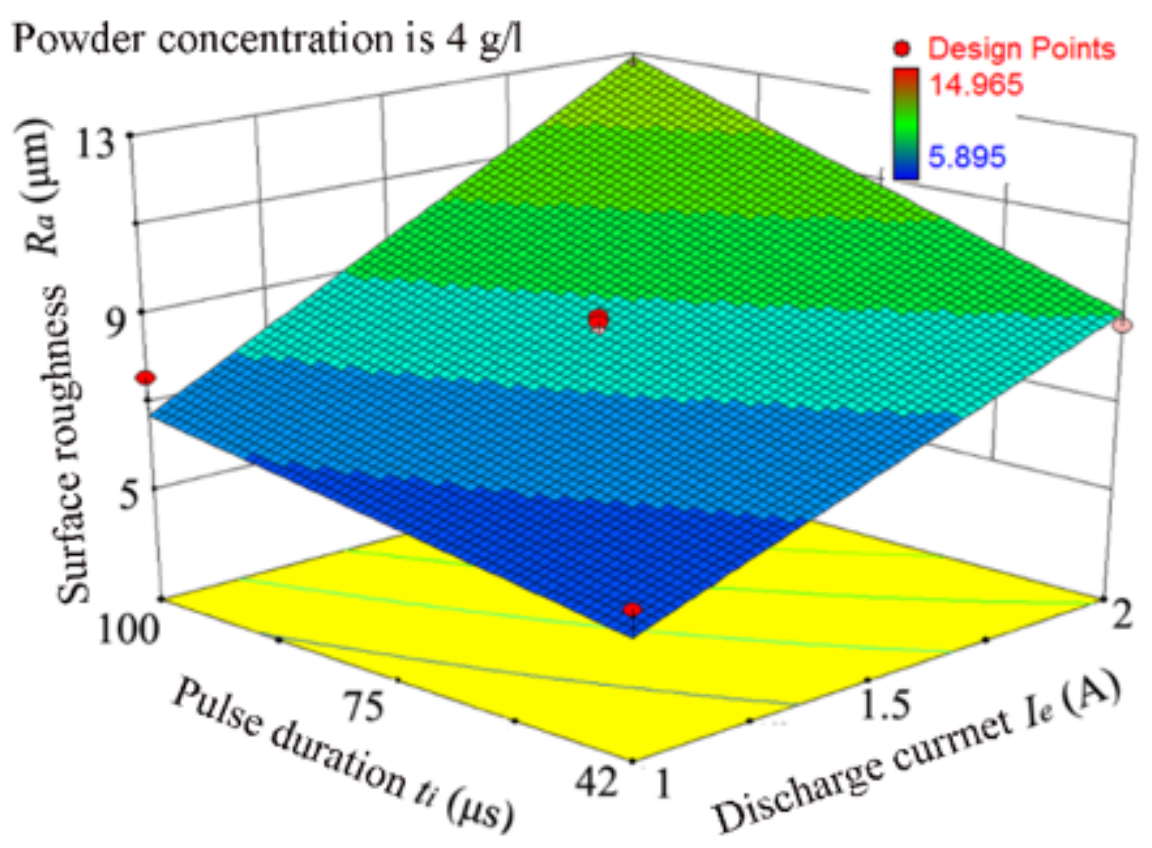

Figure 10

Variations of surface roughness with different input parameters 


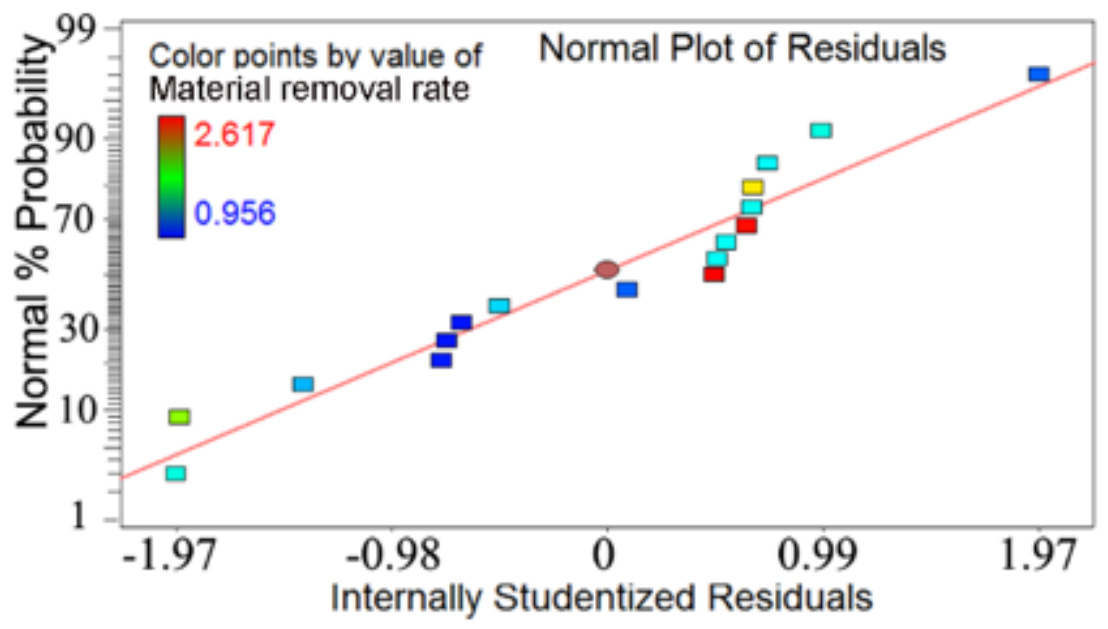

Figure 11

Normal plot of residuals for MRR

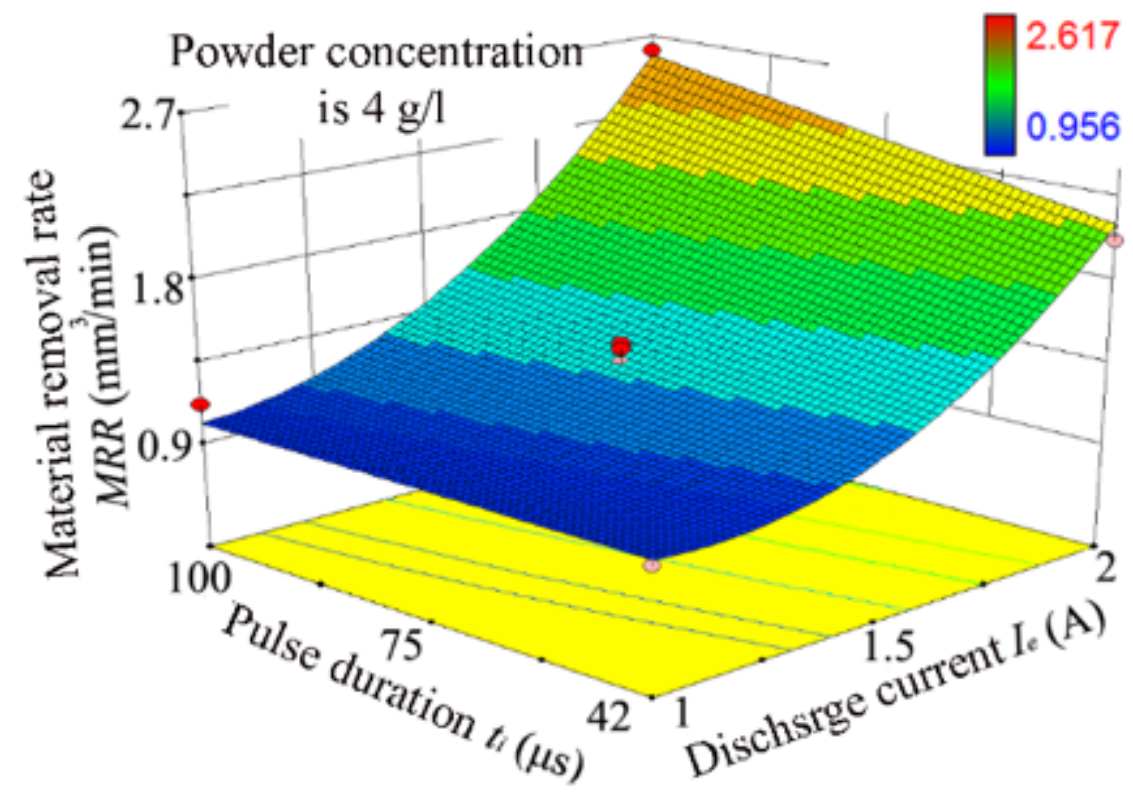

Figure 12

Effect of discharge current and pulse duration on MRR 


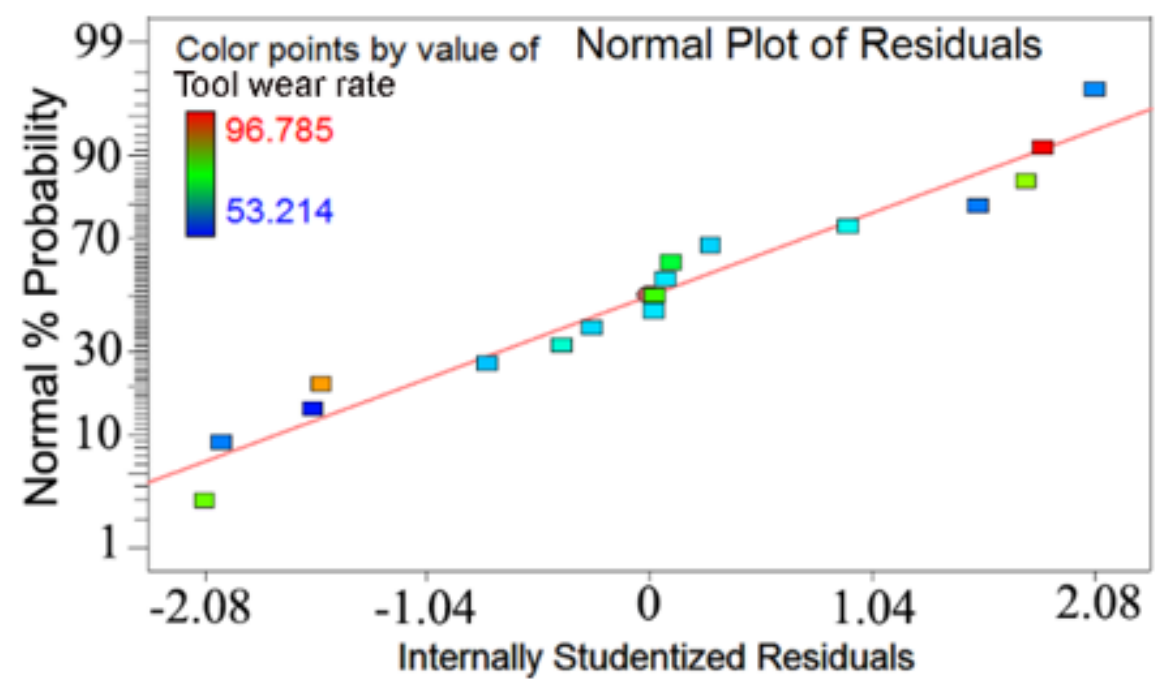

Figure 13

Residual plot for TWR

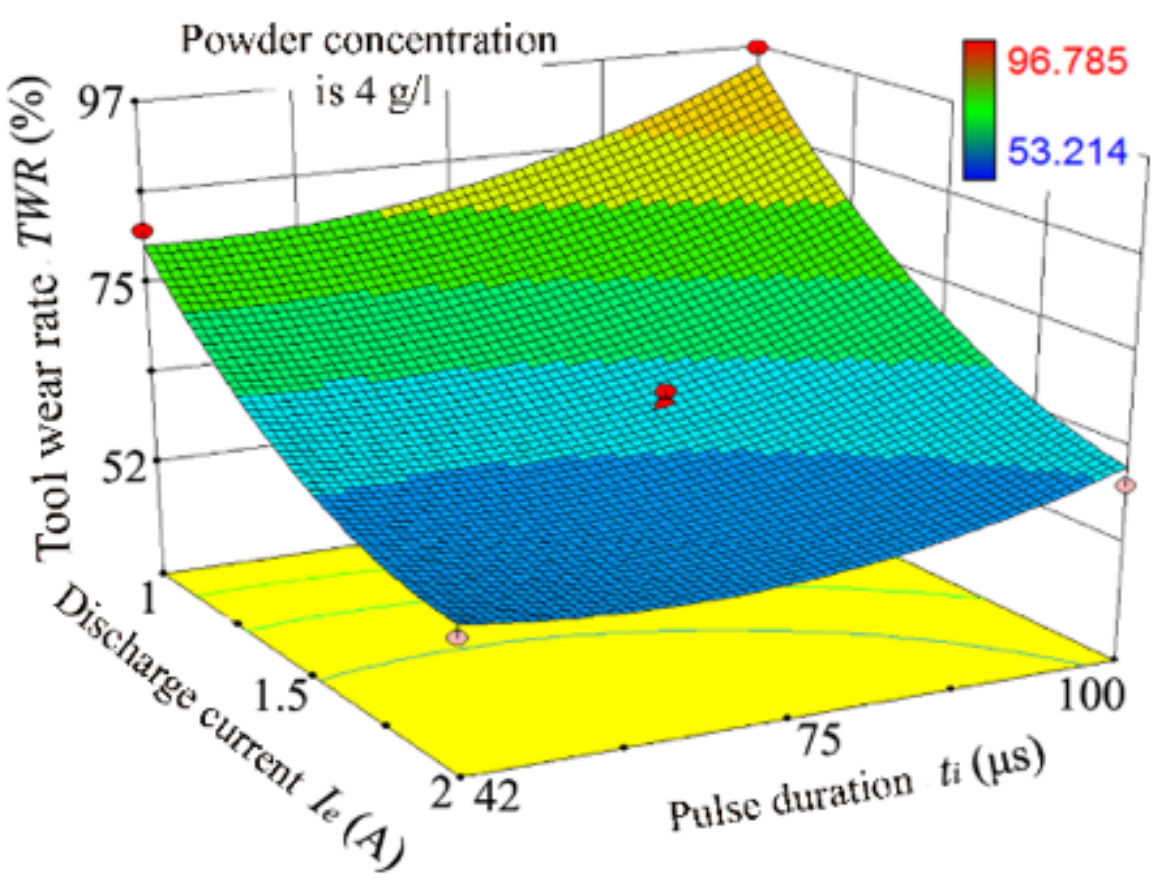

Figure 14

Effect of discharge current and pulse duration on TWR 


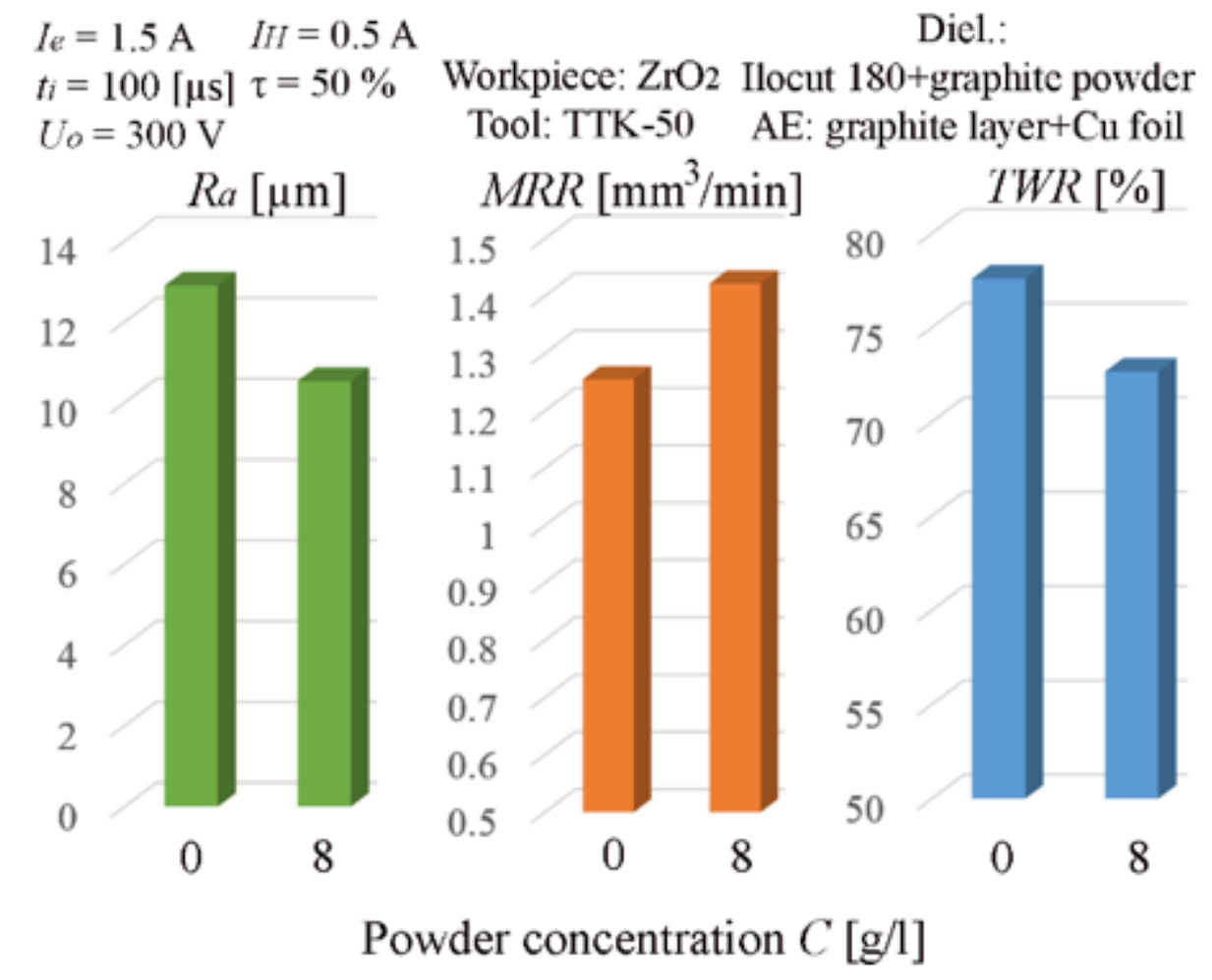

Figure 15

Effect of graphite powder concentration 